\title{
Article
}

\section{Effects of structure on noise in very thin particulate data storage media}

Mercer, Tim, Bissell, Philip and Tatarasanu, Ionel

Available at http://clok.uclan.ac.uk/11287/

Mercer, Tim ORCID: 0000-0002-1557-2138, Bissell, Philip ORCID: 0000-00028024-1757 and Tatarasanu, lonel (2007) Effects of structure on noise in very thin particulate data storage media. Journal of Magnetism and Magnetic Materials, 316 (2). pp. 199-202.

It is advisable to refer to the publisher's version if you intend to cite from the work.

For more information about UCLan's research in this area go to

http://www.uclan.ac.uk/researchgroups/ and search for < name of research Group>.

For information about Research generally at UCLan please go to http://www.uclan.ac.uk/research/

All outputs in CLoK are protected by Intellectual Property Rights law, including Copyright law. Copyright, IPR and Moral Rights for the works on this site are retained by the individual authors and/or other copyright owners. Terms and conditions for use of this material are defined in the policies page. 


\section{Author's Accepted Manuscript}

Effects of structure on noise in very thin particulate data storage Media

T. Mercer, P.R. Bissell, I. Tatarasanu

PII:

S0304-8853(07)00166-7

DOI: doi:10.1016/j.jmmm.2007.02.070

Reference: MAGMA 53570

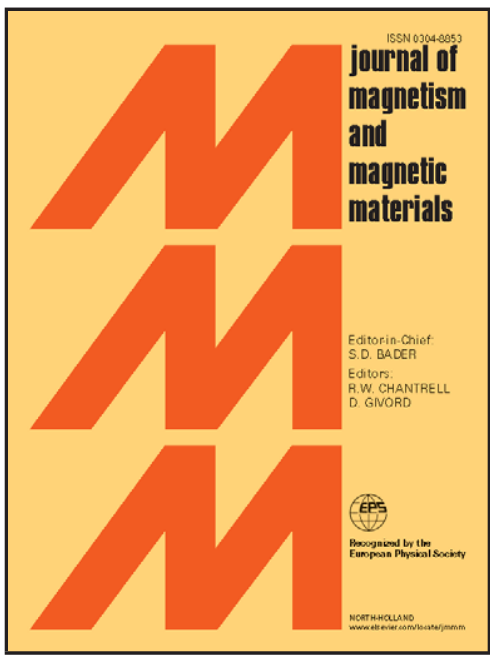

To appear in: Journal of Magnetism and www.elsevier.com/locate/jmmm Magnetic Materials

Cite this article as: T. Mercer, P.R. Bissell and I. Tatarasanu, Effects of structure on noise in very thin particulate data storage Media, Journal of Magnetism and Magnetic Materials (2007), doi:10.1016/j.jmmm.2007.02.070

This is a PDF file of an unedited manuscript that has been accepted for publication. As a service to our customers we are providing this early version of the manuscript. The manuscript will undergo copyediting, typesetting, and review of the resulting galley proof before it is published in its final citable form. Please note that during the production process errors may be discovered which could affect the content, and all legal disclaimers that apply to the journal pertain. 


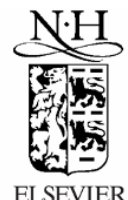

Journal of Magnetism and Magnetic Materials 00 (2007) 000-000

www.elsevier.com/locate/jmmm

\title{
Effects of structure on noise in very thin particulate data storage media
}

\author{
T. Mercer ${ }^{\mathrm{a}, \mathrm{b}, *}$, P.R. Bissell ${ }^{\mathrm{a}}$, I. Tatarasanu ${ }^{\mathrm{a}}$ \\ ${ }^{a}$ Centre for Materials Science, University of Central Lancashire, Preston PR1 2HE, UK \\ ${ }^{b}$ Department of Physics, University of Liverpool, Liverpool L69 7ZE, UK
}

Elsevier use only: Received date here; revised date here; accepted date here

\begin{abstract}
The effects of structure on noise in very thin particulate data storage tapes have been investigated using DC and tone-noise methods. The results from a set of five commercial development tapes indicate that large structural correlations of size $\sim 5 \mu \mathrm{m}$ become increasingly apparent as the magnetic layer of the tapes becomes thinner over the range $140-50 \mathrm{~nm}$. As the samples were fabricated from identical particles (MP4 - length $\sim 60 \mathrm{~nm}$ ) using the same double coating process, and with the tone-noise results showing comparable top surface roughness, these findings are consistent with large in-plane structures at the magnetic/non-magnetic interface that may be expected from mixing effects during production drying. Since this interface moves ever closer to the head with increasing data density, its effects on media noise will become increasingly important.
\end{abstract}

(C) 2007 Elsevier B.V. All rights reserved

PACS: 05.40.Ca; 75.50.Ss; 75.50.Tt;

Keywords: Metal Particles; Micromagnetic Noise; Nanoparticulate Structure; Dual Layer Tape; Double Coating

\section{Introduction}

The continuing increase in data densities of particulate recording media has been realised in the advanced metal particle (MP) tape formats now being used for backup/archive purposes. For example, the 'linear tape - open' (LTO) format has quickly established itself from a 2001 baseline shipment (100 Gbytes per cartridge) to the $3^{\text {rd }}$ generation tape (400 Gbytes per cartridge) now available as a commercial product and with a clearly defined roadmap for at least another three generations. The subsequent drive of the technology firmly into the nanoscale [1] (particle length 'tens' nm) gives added impetus to academic research interested in the magnetic structures and interactions of assemblies of magnetic nanoparticles.

The development of double coating construction techniques is an important aspect of the high data densities now achievable in these advanced tapes. Here, a very thin magnetic layer is laid on a non-magnetic undercoat and, following orientation of the magnetic particles along the direction of the tape, both are dried as an entity before calendaring and slitting to the final desired tape width. The rise in data densities has been accompanied by a necessary decrease in size of both the particles and thickness of the magnetic layer alongside an increase in read-head sensitivity such that media noise has become the limiting factor to further density increases. Previous studies have shown that the DC noise characteristics from the surface, bulk and lower interface of the magnetic layer are different and that in thick tapes (> $300 \mathrm{~nm})$ the bulk dominates, whereas in thin tapes ( $150 \mathrm{~nm})$, the top surface is dominant [2]. In this paper we report an investigation of five very thin tapes $(140-50 \mathrm{~nm})$ showing the effect of structure on noise as the magnetic/non-magnetic interface moves ever closer to the head in these advanced tape formats.

\section{Experimental Details}

Noise measurements were carried out on an open reel-toreel bench tester as shown in the schematic of .Fig. 1. Computer controlled speed, tension and direction was used to

* Corresponding author. Tel.: +44-1772-893551; fax: +44-1772.-892996

E-mail address: tmercer1@uclan.ac.uk / tim.mercer@physics.org. 


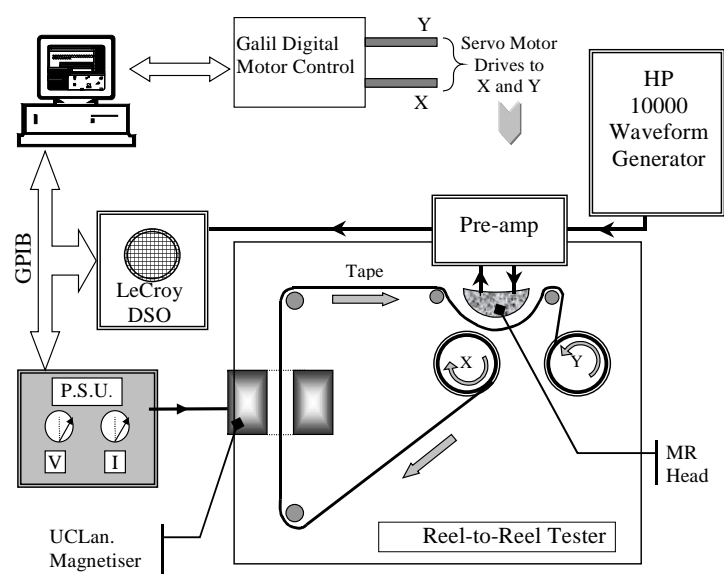

Fig. 1. Schematic of the reel-to-reel bench tester and noise measurement setup.

pass the tape over a suitable high density magnetoresistive (MR) head (Seagate LTO-1) at $2.74 \mathrm{~ms}^{-1}$ under $1 \mathrm{~N}$ in either direction. The voltage-time series produced was captured over $2 \times 10^{6}$ points at a rate of $100 \times 10^{6}$ samples/s using a LeCroy digital storage oscilloscope (DSO) and a power spectrum over $0-12.5 \mathrm{MHz}$ was then obtained using the DSO fast Fourier transform (FFT) software. This chosen frequency span and tape speed results in the technique being able to probe the media structure down to an equivalent information wavelength on the tape of $\sim 200 \mathrm{~nm}$. For the tone measurements, a 2.5 $\mathrm{MHz}$ digital write signal (TTL square wave) was used throughout.

A set of five commercial development tapes was used as detailed in table 1 . The samples were produced from identical particles (MP4 - fourth generation of length $\sim 60 \mathrm{~nm}$ ) using the same double coating technique but with each one having a different magnetic layer thickness, $t$, resulting in very thin tapes within the range $140>t>50 \mathrm{~nm}$.

\section{Results and discussion}

The results of the tone noise measurements are shown in Fig. 2. The main replay peak at the recorded frequency of 2.5 $\mathrm{MHz}$ is clearly dominant with lesser peaks observed at the

Table 1

MP4 tape samples and their characteristics

\begin{tabular}{lllll}
\hline $\begin{array}{l}\text { MP4 } \\
\text { Tape }\end{array}$ & $\left.\begin{array}{l}\text { Mrt } \\
(\text { memu cm }\end{array}{ }^{-2}\right)$ & $\begin{array}{l}\text { Coercitivity } \\
\mathrm{H}_{\mathrm{C}}(\mathrm{kOe})\end{array}$ & Squareness & $\begin{array}{l}\text { Thickness } \\
(\mathrm{nm})\end{array}$ \\
\hline A (3.6) & 3.6 & 2.51 & 0.895 & 136 \\
B (3.0) & 3.0 & 2.51 & 0.884 & 114 \\
C (2.5) & 2.5 & 2.52 & 0.886 & 95 \\
D (1.8) & 1.8 & 2.54 & 0.869 & 70 \\
E (1.5) & 1.5 & 2.55 & 0.861 & 58 \\
\hline
\end{tabular}

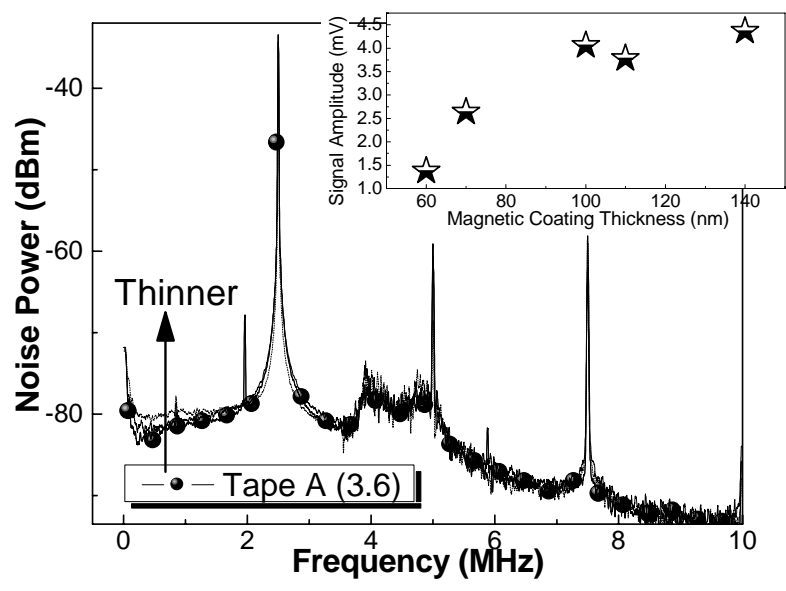

Fig. 2. Tone noise measurements for the five tapes. Whilst the sideband noise of the 'skirts' around the $2.5 \mathrm{MHz}$ signal is comparable, a trend in the lower broadband frequencies can be discerned, showing an increase in noise power as the magnetic layer becomes thinner. The increase in signal amplitude with magnetic coating thickness is shown in the inset.

harmonics. It should be noted that the presence of even harmonics, albeit smaller than the next odd harmonic, would not be unexpected as a consequence of the loss of replay signal shape and subsequent analogue signal processing of the read-channel used in this investigation. The broad 'bump' feature that is apparent over $4-5 \mathrm{MHz}$ was found to be caused by the reel servo-motors, with an initial investigation showing that this could be reduced if required by screening the motors in a grounded aluminium case.

Although not apparent on the logarithmic scale of the main plot of Fig. 2, the inset shows that the replay signal is consistent with the decreasing Mrt values (remanent magnetization $\mathrm{x}$ thickness) of Table 1 showing a reduction in amplitude with magnetic layer depth. However, the sideband noise of the 'skirts' either side of the $2.5 \mathrm{MHz}$ signal shows no variation with thickness. As sideband noise can be used as a measure of the top surface roughness [3], where the resultant variation in head-media spacing leads to amplitude modulation of the intrinsic signal, this indicates the tapes have similar contact smoothness, giving confidence in the consistency of the coating process between tape samples.

Looking at the broadband noise of Fig. 2, a trend can be seen at the lower frequencies where an overall increase in noise is observed with decreasing media thickness. Previous experimental [2] and modeling [4] studies have shown that large associations (e.g. clusters of magnetic particles formed in the wet stages of the manufacturing process) result in noise maxima in both of the magnetically saturated states. Hence, this indication of large (long wavelength) features was investigated further by using DC saturated noise measurements, the results of which are shown in Fig.3. Here, a distinct trend at the lower frequencies is evident, with a peak feature at about $600 \mathrm{kHz}$ becoming increasingly dominant as the magnetic layer becomes thinner. Fig. 4 clearly illustrates the trend, plotting the noise power of this $600 \mathrm{kHz}$ point as a 


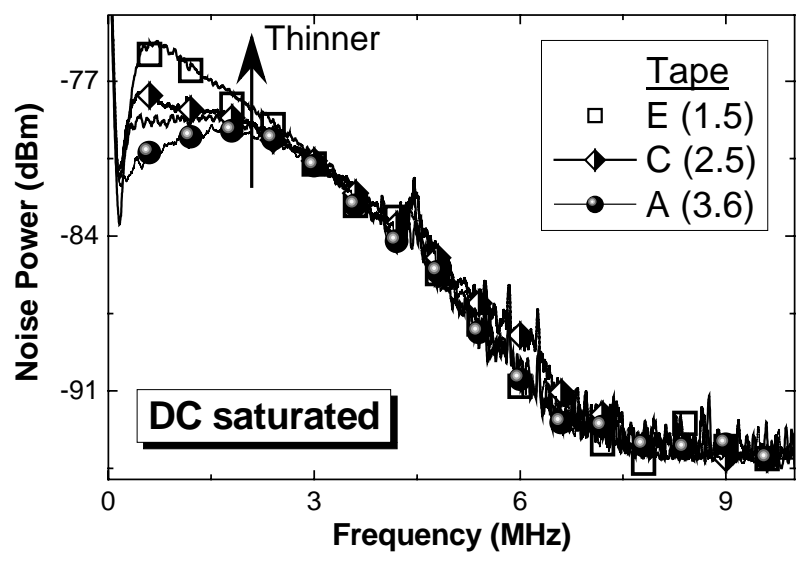

Fig. 3. DC noise measurements. Each tape was magnetically saturated using a uniform field to eliminate field gradient effects associated with a conventional write-head. A distinct trend is observable around $600 \mathrm{kHz}$, with a peak feature that becomes increasingly dominant with the reduction in tape thickness.

function of magnetic coating thickness, which results in the linear correlation (on a logarithmic scale) shown.

For our tape speed of $2.7 \mathrm{~ms}^{-1}$, the peak corresponds to a wavelength on the tape of $4.6 \mu \mathrm{m}$ and is thus indicative of large magnetic correlations becoming more apparent as the coating becomes thinner. This is large compared to the coating thickness of $<140 \mathrm{~nm}$ or the particle size of $\sim 60 \mathrm{~nm}$, suggesting in-plane structures. Assuming perturbations at the magnetic/non-magnetic interface (during the wet coating stage) produce irregularities along the tape length of this size order, this is consistent with an increase in the stray field generated by these large correlations as the interface gets closer to the read head. Other large scale and periodic interboundary features have been reported elsewhere [5], where investigations using finite element fluid dynamics have shown that violent vortex motion in the magnetic layer may be expected in double coating techniques at the point where it is laid down on the still wet under-layer. Furthermore, by applying the DC saturated state using the uniform field of an electromagnet, the field gradients over media layer thickness, as produced by the 'write bubble' of a conventional writehead, are not present. This gives additional confidence in these results as it means that any features at the individual sub-layer of the magnetic/non-magnetic boundary are subject to the same in-plane applied field regardless of depth and hence their unchanged magnetic micro-structural noise characteristic would become more apparent as the layer moves closer to the read-head.

As tapes become thinner, the noise features of this boundary will become more dominant and thus work is now underway to investigate this phenomena further using modulation of the DC states. Additional work is planned to combine the results of this subsequent study with computer simulations.

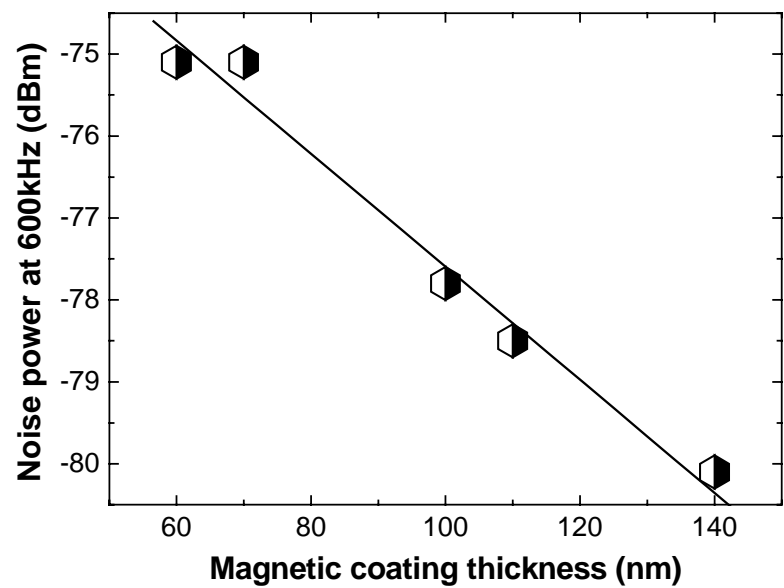

Fig. 4. Noise power at $600 \mathrm{kHz}$ as a function of media thickness. A clear linear correlation on this logarithmic scale is evident, emphasizing the significant increase in the peak feature as the magnetic layer becomes thinner.

\section{Conclusions}

The effects of media structure on the noise of advanced particulate media have been investigated as a function of magnetic layer thickness. The results indicate that large magnetic correlations become increasingly apparent as the media thickness reduces. As these structures are very large with respect to the layer depth, these findings are consistent with in-plane periodic variations at the magnetic/non-magnetic interface formed during the wet stages of the double coating process. With the decrease in media thickness that is required for further data density increases, these structures will move closer to the head and thus warrant further study.

\section{Acknowledgements}

The authors wish to acknowledge financial support from the Information Storage Industry Consortium "Advanced Magnetic Tape Storage Technology Program”, They are also grateful to staff from HP Peripherals, Bristol U.K for loan of the bench tester and wish to thank Dr. Mike Sharrock of Imation, Oakdale MN and Dr. Geoff Spratt of HP Boise ID and their colleagues for helpful advice and technical support.

\section{References}

[1] S. Kulkami, Imation Corporation White Paper, http://www.imation.com/ products/pdfs/IMN_TeraAng_WhitePaper.pdf

[2] T. Mercer, P.R. Bissell, P. Ardeleanu, L. Stoleriu, A, Stancu, J. Appl. Phys. 93 (2003) 6334.

[3] A. Roesler, J. Zhu, J. Appl. Phys. 183 (2002) 8745.

[4] D.A. Parker, G.E. Kay, P.R. Bissell, T. Mercer, J. Magn. Magn. Mater. 242-245 (2002) 366.

[5] R.J. Veitch, A. Ilmer, W. Lenz, V. Richter, J. Magn. Magn. Mater. 193 (1999) 279. 